\title{
Subject Index Vol. 16,1995
}

Alkaline phosphatase, placental

394 Anti-idiotype antibody 39 Biliary glycoprotein 23 Breast and colonic tumors 47

- $\quad$ cancer $222,243,290$

CA 15-3 serum level 243

CA125 374

Cancer 32

imaging 62

therapy 62 Carcinoembryonic antigen 10,23,

39,62 CD66 17 CEA 32,42

- $\quad$ family 17

Cell culture(s) 353,374

cycle 222 Cervical cancer 254 Chromosomal localisation 10 Colon cancer 281

tumor 261 Cutoff point 243 CYFRA21-1 345 Cytokeratin 19345 Diagnostic tool 42 DNA 385

Domain organisation 10 Endometrial cancer 254 Expression patterns 10 Flow cytometry 17,385

B-Glucuronidase $394 \mathrm{GnRH}$ analogs 268 Gonadal steroids 353 Gonadotropins 268, 374

Granulosa cell tumors 268 Gynecologic malignancy 345 Human tumor cells 213 Immune

changes 365 Immunofluorescence 222 Immunohistochemistry 281 Immunohistopathology 42

Immunotherapy 39 Indomethacin 230 Intercellular adhesion 23 Interferon-o1/8, $365 \mathrm{Ki}-67$ antigen 222

Luteinizing hormone 374 Lymphokine-activated killer

activity 230 Markers 243 MCF-7 222 Melanoma 365 ß2-Microglobulin 290 Min mice 47

Monoclonal antibodies 10,39,62,281 Myogenic differentiation 23 Nephroblastoma 385

Nonspecific cross-reacting antigens 17 Oncodevelopmental biology 394 Ovarian cancer 254, 268

- $\quad$ carcinoma 374

Performance status 230

Phosphotyrosine phosphatase 261

Pituitary neoplasms 353

Ploidy 385

Predictivity 243

Pregnancy-specific glycoprotein 10 Progesterone receptor 222

- $\quad$ - forms A and B, human 254

'Prostatic' acid phosphatase 394

Radioimmunoconjugates 62

Radioimmunodetection 62

Radioimmunotherapy 62

Reference value 345

Regan isoenzyme 394

Renal cancer 365

Reverse transcriptase/polymerase 
chain reaction 10 Seminoma 394 Soluble ICAM-1 290

$\mathrm{IL} \cdot 2290$

IL-2R 290 Somatostatin 261 Spatiotemporal expression 47 Specificity 243

Spheroids 213

Stage of disease 230

Steroid receptors 353

Theca cell tumors 268

Tissue organization 213

TJ4C4 281

Transfectants 17

Tumor marker(s) 32, 47, 281, 345

405 